\title{
Immune Response of Gamma-Irradiated Inactivated Bivalent Polio Vaccine Prepared plus Trehalose as a Protein Stabilizer in a Mouse Model
}

\author{
Maryam Mollaei Alamuti ${ }^{a} \quad$ Mehrdad Ravanshad $^{a} \quad$ Farahnaz Motamedi-Sedeh $^{\mathrm{b}}$ \\ Arezoo Nabizadeh $^{a}$ Elham Ahmadia,c Seyedeh Maedeh Hossieni ${ }^{d}$

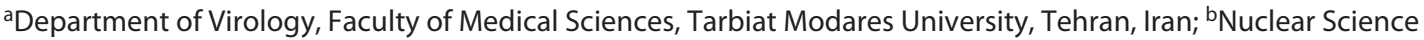 \\ and Technology Research Institute (NSTRI), Nuclear Agriculture Research School, Tehran, Iran; 'Division of Infectious \\ Diseases and Immunology, Department of Medicine, University of Massachusetts Medical School, Worcester, MA, \\ USA; ${ }^{d}$ Faculty of Medical Sciences, Tehran University of Medical Sciences, Tehran, Iran
}

\section{Keywords}

Adjuvant · Immunity · Poliovirus · Radiation · Vaccine

\begin{abstract}
Introduction: Poliovirus causes paralysis by infecting the nervous system. Currently, 2 types of polio vaccine are given in many countries in polio eradication program including inactivated polio vaccine (IPV) and oral polio vaccine (OPV). Because of OPV-related paralysis, OPV should be replaced by IPV. Methods: The aim of this study was to prepare the gamma-irradiated IPV and determine its effectiveness compared with the commercial vaccine (OPV) in the mouse model. The virus titration of OPV was determined and then inactivated by the appropriate dose of gamma radiation into an irradiated vaccine formula. The vaccine was inoculated in BALB/C mice in 2 different formulations of intramuscular injection with 2-week intervals. The level of anti-polio-neutralizing antibody and polio-specific splenocyte proliferation assay were evaluated by collecting the blood samples and spleens of the vaccinated groups with conventional vaccine and irradiated vaccine. Results: There was a significant increase in the neutralizing antibody titration between all of the vaccinated
\end{abstract}

karger@karger.com www.karger.com/int

Karger $\stackrel{\text { ' }}{5}$

GOPEN ACCESS
(C) 2021 The Author(s)

Published by S. Karger AG, Basel

This is an Open Access article licensed under the Creative Commons Attribution-NonCommercial-4.0 International License (CC BY-NC) (http://www.karger.com/Services/OpenAccessLicense), applicable to the online version of the article only. Usage and distribution for commercial purposes requires written permission. groups and negative control group (A) $(p<0.05)$. And it shows that the IPV by gamma irradiation has the highest antibody titration. Also, the increasing of stimulation index value in the $B^{*}$ group, $F$ group, and $G$ group was the most against other groups. Furthermore, the neutralizing anti-serum titer and splenic lymphocyte proliferation assay show humoral and cellular immunity were significantly increased in the irradiated vaccine group as compared with conventional group. Conclusion: According to the results, gamma-irradiated IPV could induce humoral and cellular immunity in vaccinated mouse groups, so the irradiated poliovirus could be recommended as a good candidate vaccine to prevent the transport of poliovirus to the central nervous system and thus protect against paralysis. @ 2021 The Author(s)

Published by S. Karger AG, Basel

\section{Introduction}

Historically, poliomyelitis is one of the most important acute viral infections of human central nervous system leading to paralysis. There is no treatment for the resulted infection by all 3 poliovirus serotypes, and 
there have been many reports of poliovirus infection in developing countries. Available preventive vaccines consist of live-attenuated and inactivated viruses. Liveattenuated oral polio vaccine (OPV) is effective and could induce lifelong immunity, but in some cases, it could induce vaccine-related paralysis by producing mutant strains, which could be a threat for polio eradication. According to the WHO polio eradication program, most countries must maintain the polio immunization, and both mass vaccination and OPV should be replaced by inactivated polio vaccine (IPV). In this study, we try to introduce low-cost IPV by using gamma radiation that could potentially be a good candidate for this purpose [1].

Vaccination is an effective method to control infectious diseases. Poliomyelitis caused by poliovirus is an acute viral infection in the central nervous system that may cause paralysis, poliomyelitis, and disability. Poliovirus is one of the members of Enterovirus genus and Picornaviridae family. There are 3 serotypes of poliovirus, and there is no cure for poliomyelitis [2]. Global polio eradication and prevention vaccines are available in 2 types: live-attenuated oral polio vaccine (OPV) and an inactivated polio vaccine (IPV). The current vaccines have different strengths and weaknesses. OPV vaccine is very effective but can cause vaccine-associated paralytic polio by generating mutant strains, and it can spread from person to person. However, IPV is a high-cost vaccine and does not induce sufficient and sustained mucosal immunity, but it is less effective to prevent transmission. Also, IPV is very protective against polio infections. The risk of paralytic polio associated with OPV and the WHO updated polio immunization program spurred most of the countries to switch to IPV [3]. Different production technologies such as virus inactivation and vaccine formulation have been commonly used for vaccine preparation. Current IPV vaccine has some difficulties in production process and costs. So many laboratories are trying to produce low-cost and affordable next-generation IPV [4].

In this study, we tried to introduce low-cost IPV by using gamma radiation that could be a good candidate for this purpose. Based on the gamma radiation technology, gamma rays are a group of short electromagnetic rays that have a little impact on the antigenic property of proteins compared to chemical treatment such as formalin. In this research, radiation technology is incorporated in the principal steps of polio vaccine preparation [5].

Gamma-Irradiated Inactivated Bivalent Polio Vaccine

\section{Material and Methods}

\section{Cell Culture and Poliovirus Seed}

Vero cell lines were grown in DMEM media with $10 \%$ fetal bovine serum and were incubated at $37^{\circ} \mathrm{C}$ and $5 \% \mathrm{CO} 2$ in a humidified incubator. The type 1 and 3 live-attenuated poliovirus seed lots were obtained from the Razi Vaccine and Serum Research Institute, Karaj, Iran. When the cells reach $90 \%$ confluency, the monolayers were infected with the attenuated poliovirus. Following the observation of cytopathic effects (CPEs), the virus-containing culture supernatants were harvested and used for virus titration by tissue culture infectious dose $\left(\mathrm{TCID}_{50} / \mathrm{mL}\right)$ assay.

\section{Virus Cultivation and Titration}

The attenuated poliovirus titer was determined by the end point dilution assay. Vero cells were grown for 2 days in DMEM medium and were infected by logarithmic serial dilution of virus. CPE formation was observed for 7 days compared with uninoculated control culture and then virus titration was calculated by the Reed and Muench method [6].

\section{Virus Inactivation by Gamma Irradiation}

Gamma cell instrument, Nordian model 220, at a dose rate of 2.07 Gy/s and activity of $8,677 \mathrm{Ci}$ was used to cripple poliovirus genomic RNA and to inactivate virus infectivity. Gamma ray doses of $5,10,20$, and $25 \mathrm{kGy}$ were administered to 8 viral vials of liveattenuated vaccine, and 2 sample replicates were irradiated for each dose under frozen conditions $\left(-70^{\circ} \mathrm{C}\right)$. The titers of irradiated virus samples were obtained by the $\mathrm{TCID}_{50}$ method, and then a dose/response curve was drawn using Origin software. The $\mathrm{D}_{10}$ value (dose of gamma radiation, which can decrease 1 logarithmic cycle of virus population) and optimum dose of gamma rays for virus inactivation were determined according to the dose/response curve. Finally, 2 vials of bivalent polioviruses that include $50 \mathrm{~mL}$ of the poliovirus, one of them plus $20 \%$ trehalose $(1 \mathrm{M})$ (a disaccharide of glucose, as a protein protectant) and another without trehalose, under frozen conditions were irradiated by the optimized dose of gamma ray and used for safety test on cell culture (during 4 blind cultures) to confirm complete virus inactivation [7].

\section{Animals}

Twenty-four female Balb/c mice of 4-6 weeks were purchased from the Pasteur Institute (Tehran, Iran) and divided into 8 groups ( 3 mice for the negative control group, A group); all animals were maintained in well standard of animal care conditions in an animal house facility. The animal experiments were carried out according to the international guidelines and were approved by the Medical Ethics Committee of the Tarbiat Modares University (Tehran, Iran).

The laboratory animal groups included LD (low dose) of irradiated vaccine (with TCID $\left._{50}: 3 \times 10^{3.7}\right)(50 \mu \mathrm{L})(\mathrm{B}$ group), HD (high dose) of irradiated vaccine (with $\left.\mathrm{TCID}_{50}: 6 \times 10^{4.7}\right)(50 \mu \mathrm{L})\left(\mathrm{B}^{*}\right.$ group), $\mathrm{LD}$ of irradiated vaccine plus alum adjuvant $(50 \mu \mathrm{L})(\mathrm{C}$ group), LD of irradiated vaccine $(100 \mu \mathrm{L})$ (D group), LD of irradiated vaccine plus alum adjuvant $(100 \mu \mathrm{L})$ (E group), LD of irradiated vaccine plus trehalose $(100 \mu \mathrm{L})$ (F group), and finally the Sabin vaccine (OPV) $(100 \mu \mathrm{L})$ as well as the negative control. The vaccines were injected intramuscularly in the mice 3 times at 2 -week intervals. The animals were euthanized 2 weeks after the last vaccination, the mice blood was collected by cardiac puncture,

Intervirology 2021;64:140-146 141 
and the spleens were removed. The splenic lymphocytes proliferation assay was done by the MTT method (Cell Proliferation Kit 1 (MTT), Roche (Cat No: 11-465-007-001)), and the mice serum was separated from the blood sample for the serum neutralization test (SNT).

\section{Serum Neutralization Test}

Vero cells were grown to a confluent monolayer in 96-well microplates. The functional anti-polio antibodies were monitored by the SNT [8]. Vero cells were infected by serial dilution of serum samples that were collected from vaccinated mice and mixed with $100 \mathrm{CCID}_{50}$ of live virus sample. The neutralizing antibody titers are expressed as reciprocals of the highest serum dilutions that showed complete virus neutralization.

\section{Splenic Lymphocyte Proliferation Assay by the MTT Method}

In order to assess splenic lymphocyte proliferation, the MTT assay was performed. Briefly, MTT allows the quantitative measurement of cell death in cell culture and shows the lymphocyte proliferation and function.

The spleens of the vaccinated mice were removed aseptically 2 weeks after boost immunization. The single splenic lymphocyte suspensions were multiplied in 96-well plates at $5 \times 10^{4}$ cells/well by RPMI1640 plus $10 \%$ fetal calf serum at $37^{\circ}$ and $5 \%$ CO2. The splenic cells were stimulated with $50 \mu \mathrm{L}$ of phytohemagglutinin $(50$ $\mu \mathrm{g} / \mathrm{mL}$; as a positive control), with $3 \mu \mathrm{L}$ of irradiated inactivated poliovirus (types 1 and 3 , with TCID $_{50}$ equal $10^{5.5} / \mathrm{mL}$ ) in triplicates (as an antigen-specific stimulation) and no antigen (as a negative control) in triplicates. After $48 \mathrm{~h}$, the MTT assay was performed by a Cell Proliferation Kit 1 (MTT; Roche), according to the manufacturer's instructions. A yellow tetrazole substrate would be reduced to a purple formazan product by living cells, and after solubilization by adding to a dissolving solution, the absorbance was quantified using a spectrophotometer at $540 \mathrm{~nm}$. Stimulation index (SI) was calculated for each sample (SI = mean of OD for stimulated wells/mean of OD for unstimulated wells) [9].

\section{Statistical Analysis}

Comparison of means of the SNT and SI results was done by the one-way ANOVA, followed by Duncan's multiple range test (SPSS software). The differences were considered to be statistically significant for $p<0.05$.

\section{Results}

\section{Virus Titration and Inactivation}

For more safety, the virus seed that has been used to prepare the inactivated vaccine has been provided from conventional live-attenuated vaccine OPV. The virus titration on Vero cells for unirradiated sample was obtained as $10^{5.5} \mathrm{TCID}_{50} / \mathrm{mL}$. The viral samples were stored in $-20^{\circ} \mathrm{C}$ and then transferred to gamma cells for irradiation. The virus titration was done after irradiation of samples in each dose of gamma ray, and the results of virus titration were calculated by the Reed and Muench method (Table 1). When a viral suspension is irradiated at in-
Table 1. Titration of irradiated and unirradiated viral samples

\begin{tabular}{llllll}
\hline Dose $(\mathrm{kGy})$ & 0 & 5 & 10 & 20 & 25 \\
\hline $\mathrm{TCID}_{50} / \mathrm{mL}$ & $10^{5.5}$ & $10^{3.75}$ & $10^{2.66}$ & $10^{2.2}$ & $10^{1.75}$ \\
\hline
\end{tabular}

$\mathrm{TCID}_{50}$, tissue culture infectious dose.

cremental doses, the number of surviving cells after each incremental dose of gamma ray may be used to construct a dose/response curve, as shown in Figure 1. The radiation resistance of the virus is measured by the decimal reduction dose ( $D_{10}$ value), which is defined as the radiation dose $(\mathrm{kGy})$ to reduce the viral load by 10 -fold (1 $\log _{10}$ ) or required for killing $90 \%$ of the first viral load [10, 11]. The infectivity of viral samples was decreased gradually with an increase in gamma radiation doses according to the dose/response curve (Fig. 1) that was drawn using Origin software and Table 1 . The $\mathrm{D}_{10}$ value (the dose of gamma radiation that decreases $1 \log _{10}$ of the viral load) was calculated as $5.34 \mathrm{kGy}$ by the Reed and Muench method. While the sterility dose of gamma radiation for complete inactivation was calculated to be $29.4 \mathrm{kGy}$ based on the $\log _{10}$ of unirradiated virus titration and $D_{10}$ value (sterility dose $=5.5 \times 5.34=29.4$ ). To evaluate the optimal inactivation dose, poliovirus was cultured in 4 blind passages as a safety test (Table 2 ). The safety test results presented in Table 2 show positive suspicious CPE for 30 $\mathrm{kGy}$ irradiated viral samples in passage 1 , but not in passages 2 and 3. It can explain some indirect effects of gamma irradiation that are caused by the radiolytic cleavage of water and created from the radiolytic cleavage of $\mathrm{O}_{2}$. So, the addition of $30-\mathrm{kGy}$ irradiated materials at high concentration would lead to a CPE in the first passage. The absence of CPE at the third and fourth passages confirmed the lack of infectious particles $[12,13]$.

Finally, the optimal dose of gamma ray that can close the viral titration to zero was obtained $30 \mathrm{kGy}$ according to dose/response curve for irradiated poliovirus and safety test results on cell culture (Table 1, 2; Fig. 1).

To evaluate the performance and immunity induction, radiated vaccine has been injected in 8 groups of murine model, including negative control, formulated irradiatedvaccine with trehalose adjuvant, formulated irradiatedvaccine with alum adjuvant (in 2 different doses of vaccine: $50 \mu \mathrm{L}$ and $100 \mu \mathrm{L}$ ), IPV (in 3 different doses of vaccine: LD-50 $\mu \mathrm{L}, \mathrm{LD}-100 \mu \mathrm{L}$, and HD-50 $\mu \mathrm{L}$ ), and conventional OPV. The sera of vaccinated animals were 
Fig. 1. Dose/response curve for irradiated poliovirus ranged from 5 to $25 \mathrm{kGy}$. TCID $_{50}$, tissue culture infectious dose.

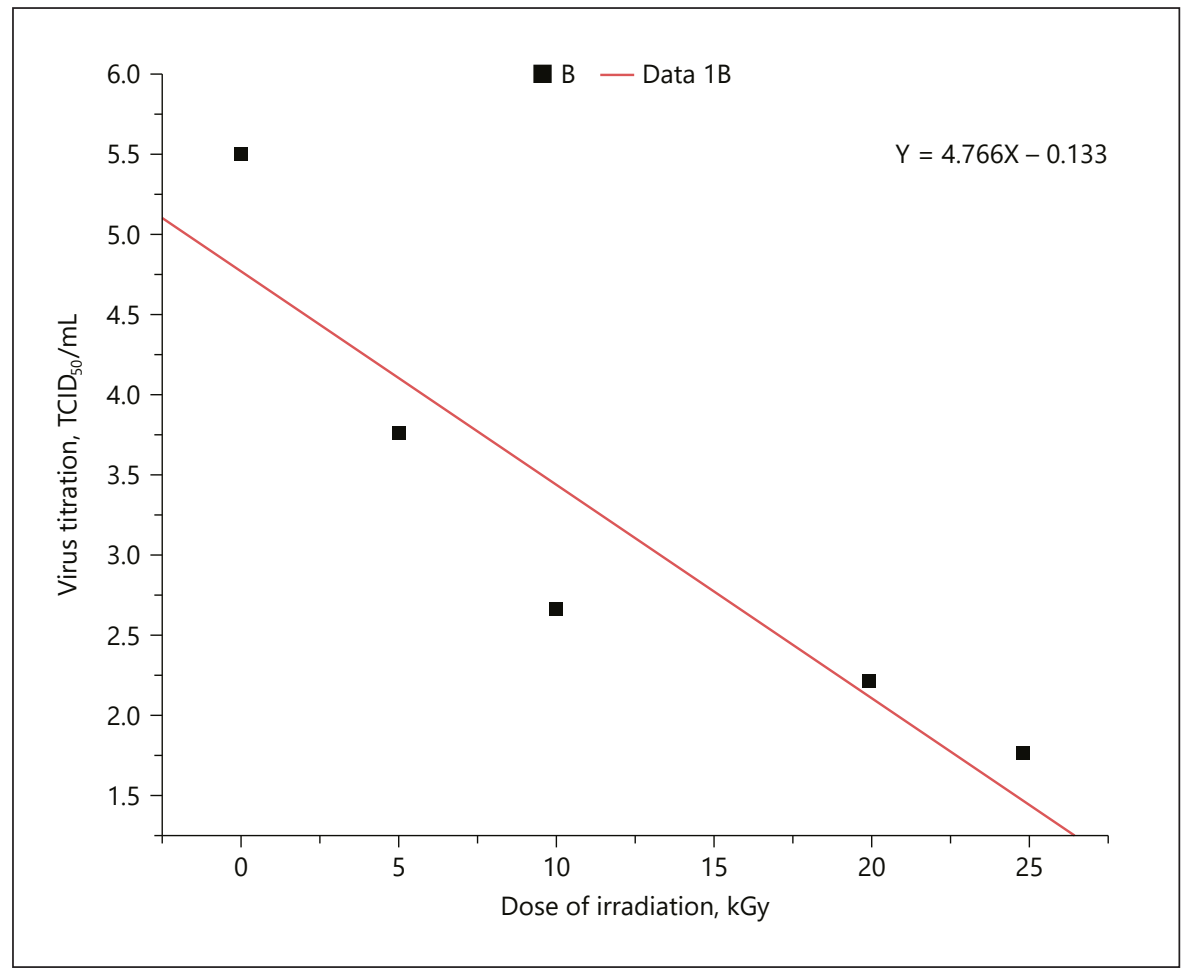

Table 2. Safety test to determine the optimal inactivation dosing based on cytopathic symptoms

\begin{tabular}{|c|c|c|c|c|}
\hline \multirow{2}{*}{$\begin{array}{l}\text { Irradiated } \\
\text { virus sample }\end{array}$} & \multicolumn{4}{|l|}{ CPE } \\
\hline & first passage & second passage & third passage & fourth passage \\
\hline 30 kGy & Positive suspicious & Negative & Negative & Negative \\
\hline 30 kGy & Negative & Negative & Negative & Negative \\
\hline 35 kGy & Negative & Negative & Negative & Negative \\
\hline 35 kGy & Negative & Negative & Negative & Negative \\
\hline
\end{tabular}

CPE, cytopathic effect.

tested by the SNT method to evaluate the anti-poliovirus antibodies. It can immunize mice particularly with trehalose as a protein stabilizer and alum as an adjuvant (Fig. 3) as well as OPV. There was the significant increasing in the neutralizing antibody titration between all of the vaccinated groups and negative control group (A) $(p<0.05)$. Also, it shows the IPV by gamma irradiation, HD-50 $\mu \mathrm{L}$ ( $\mathrm{B}^{*}$ group), and LD-100 $\mu \mathrm{L}$ (D group) have the highest antibody titration; however, the E, F, and G groups showed high antibody titration and the same of each other (Fig. 2). So, the best amount of vaccine doses is $100 \mu \mathrm{L}$ with a viral load of $3 \times 10^{3.7} \mathrm{TCID}_{50} / \mathrm{mL}$ and trehalose as the same as alum that can induce anti-polio antibody.

Gamma-Irradiated Inactivated Bivalent Polio Vaccine
The splenic lymphocyte was stimulated with $3 \mu \mathrm{L}$ of irradiation-inactivated OPV (types 1 and 3 , with TCID 50 equal $10^{5.5} / \mathrm{mL}$ ). According to Table 3 and Figure 3, the SI value in groups A and B has significant differences compared with other groups $(p<0.05)$. Also the splenic lymphocyte proliferation results were increased in groups $B^{*}, C, D, E, F$, and G. However, the increasing SI value in the $\mathrm{B}^{*}$ group (HD of irradiated vaccine- $50 \mu \mathrm{L}$ ), F group (LD of irradiated vaccine plus Trehalose-100 $\mu \mathrm{L}$ ), and $\mathrm{G}$ group (OPV-100 $\mu \mathrm{L}$ ) was the most against other groups (Fig. 3). So, the best amount of vaccine dose is $100 \mu \mathrm{L}$ with a viral load: $3 \times 10^{3.7} \mathrm{TCID}_{50} / \mathrm{mL}$, and trehalose as the same as that of OPV can induce splenic lymphocyte pro- 
Fig. 2. Comparison of the mean anti-polio antibody in vaccinated groups by SNT. Negative control (A), low dose of gammairradiated vaccine-50 (B), high dose of gamma-irradiated vaccine-100 (B*), low dose of gamma-irradiated vaccine plus alum adjuvant-50 (C), low dose of gammairradiated vaccine-100 (D), low dose of gamma-irradiated vaccine plus alum adjuvant-100 (E), low dose of gamma-irradiated vaccine plus trehalose-100 (F), Sabin vaccine (OPV)-100 (G). SNT, serum neutralization test; OPV, oral polio vaccine.

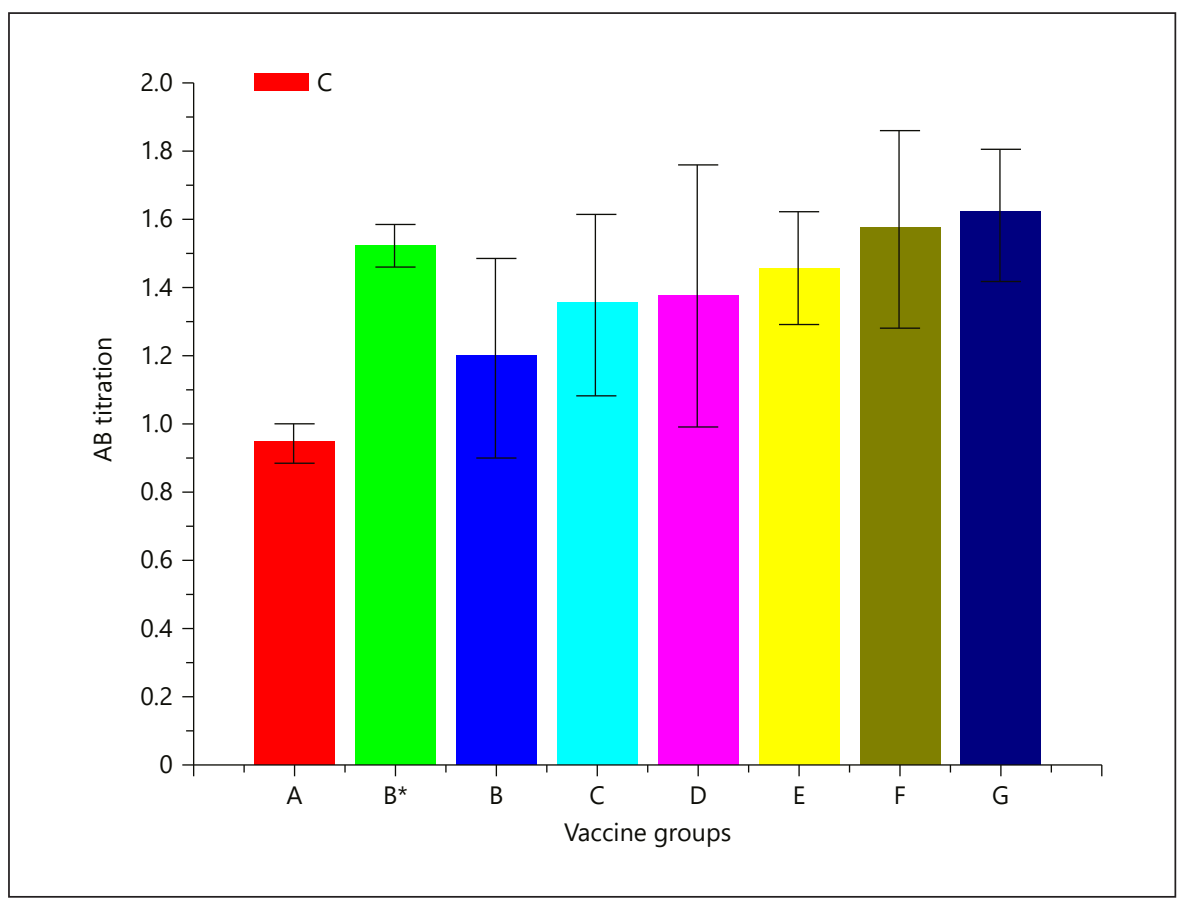

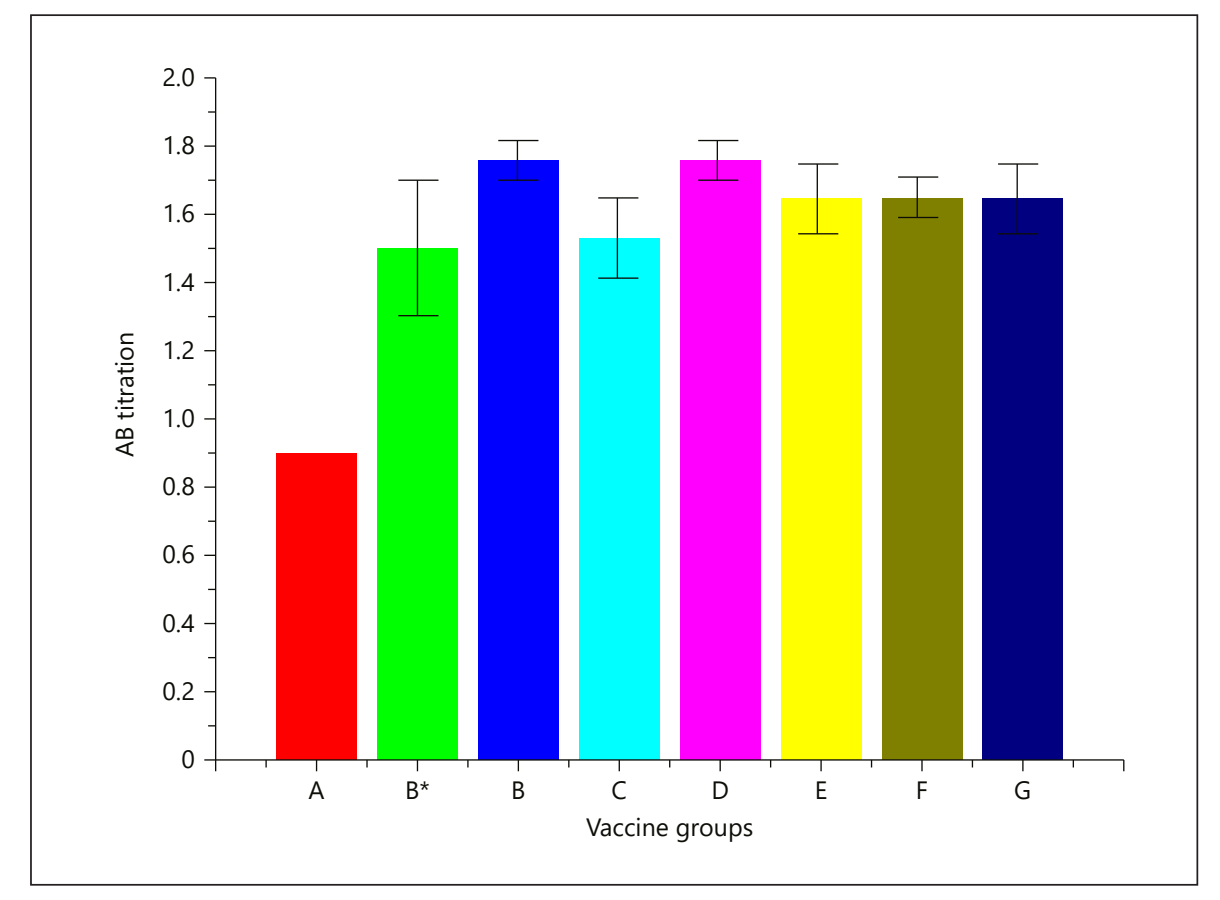

Fig. 3. SI chart for mice splenic lymphocytes with MTT assay. Negative control (A), low dose of gamma-irradiated vaccine-50 (B), high dose of gamma-irradiated vaccine-100 $\left(\mathrm{B}^{*}\right)$, low dose of gamma-irradiated vaccine plus alum adjuvant-50 (C), low dose of gamma-irradiated vaccine- 100 (D), low dose of gamma-irradiated vaccine plus alum adjuvant-100 (E), low dose of gamma-irradiated vaccine plus trehalose-100 (F), Sabin vaccine (OPV)-100 (G). SI, stimulation index; OPV, oral polio vaccine. liferation. As the results are shown in Figures 2 and 3, irradiated vaccine with a viral load of $3 \times 10^{3.7} \mathrm{TCID}_{50} / \mathrm{mL}$ plus trehalose $(100 \mu \mathrm{L})$ and OPV could enhance immune responses with a significant difference against other groups $(p<0.05)$.

\section{Discussion}

Poliomyelitis is one of the most important health problems around the world associated with lifelong movement incapability and paralysis, especially among children and young adults. Regardless of good effective- 
Table 3. The antibody titration and SI of splenic lymphocytes in vaccinated mice

\begin{tabular}{llcc}
\hline Code & Vaccine groups & Antibody titration \pm SD & SI \pm SD \\
\hline A & Negative group & $<0.9 \pm 0.00$ & $0.94 \pm 0.06$ \\
B & Low dose $-50 \mu \mathrm{L}$ & $1.5 \pm 0.05$ & $1.19 \pm 0.06$ \\
$\mathrm{~B}^{*}$ & High dose $-50 \mu \mathrm{L}$ & $1.76 \pm 0.2$ & $1.52 \pm 0.46$ \\
$\mathrm{C}$ & $\mathrm{LD}+$ alum $(50 \mu \mathrm{L})$ & $1.53 \pm 0.11$ & $1.35 \pm 0.26$ \\
$\mathrm{D}$ & $\mathrm{LD}-100 \mu \mathrm{L}$ & $1.76 \pm 0.05$ & $1.37 \pm 0.38$ \\
$\mathrm{E}$ & LD + alum $(100 \mu \mathrm{L})$ & $1.65 \pm 1.00$ & $1.46 \pm 0.16$ \\
$\mathrm{~F}$ & $\mathrm{LD}+$ trehalose $(100 \mu \mathrm{L})$ & $1.65 \pm 0.05$ & $1.57 \pm 0.28$ \\
$\mathrm{G}$ & OPV & $1.650 \pm 1.00$ & $1.62 \pm 0.19$ \\
\hline
\end{tabular}

SI, stimulation index; OPV, oral polio vaccine. ness of available IPV and OPV vaccines, there are still some problems such as safety and production cost for these vaccines. For the eradication of poliovirus and given the risk of vaccine-associated paralytic poliomyelitis and circulating vaccine-derived polioviruses, the use of OPV must be removed from all immunization activities [14]. On the other hand, based on the WHO worldwide poliovirus eradication program, countries including the Middle East, which have participated in the OPV mass vaccination program, should switch to IPV. The WHO introduced IPV in countries with OPV vaccination programs in 2013. However, the risk of the infections from OPVs will be more significant than the risk of wildtype virus infection; and finally, oral vaccines will be completely replaced worldwide [15].

The aim of the current study was to develop a new inactivation process to reduce the side effects of conventional IPV. Inactivated vaccines are more stable and safer than live vaccines. Chemical inactivation methods such as formalin inactivation have some toxic residues in the vaccine products; also some viruses may escape during the chemical inactivation. The most common chemical substances that are used in vaccine production can damage antigenic epitopes, leading to reduce immunogenicity. According to positive effects of radiation on biological reagent sterilization and pathogens inactivation, its application for safe vaccines production is increasing. Production of some inactivated vaccines by gamma irradiation such as FMD virus and HSV demonstrated that radiated inactivated viruses retained virus and antigenic structure [16-19]. Gamma ray is an ionizing radiation which is emitted from the Cobalt-60 isotope and used for virus inactivation without any change in viral proteins. In general, the optimum dose of gamma irradiation for virus inactivation is mainly dependent on radiation conditions, particularly the temperature of radiation, size, and struc- tural arrangement of viral DNA, the presence of oxygen during the irradiation process, water content, and postirradiation conditions [11].

Since the gamma radiation has a little effect on the antigenic construction, its higher penetration, and the ability to be used in frozen condition that decreases free radical damage due to the water radiolysis, it is the perfect method for virus inactivation [20-22]. A sterility assurance level (SAL) is derived mathematically, and it defines the viable viral load on the final product (vaccine) after sterilization. SAL is normally expressed as $10^{-6} / \mathrm{mL}$ for the injectable products. The sterilization dose is the minimum dose necessary to achieve the required SAL. The sterilization dose depends on (i) the first titration of viable viral load, (ii) $\mathrm{D}_{10}$ value, and (iii) SAL required for the product $[10,11]$.

In this research, the optimum dose for complete inactivation of OPV (strains 1 and 2) was obtained about 30 $\mathrm{kGy}$, and we have substituted the conventional IPV inactivation by gamma radiation inactivation based on bivalent Sabin strains to provide the efficient immunity in a low-cost process and free of live vaccine-derived polioviruses. Additionally, we have used trehalose as a protein stabilizer to preserve whole virus particle and antigenic structure intact during irradiation so it would make more effective immune induction and immunity. Finally, we can recommend the gamma irradiation technique to prepare the safe IPV without antigenic changes and with the ability of humeral and cellular immunity induction.

\section{Acknowledgements}

This work was made possible through the Research and Technology Deputy of Tarbiat Modares University, Department of Virology, Faculty of Medical Sciences, Tehran, Iran. We would like to take this opportunity to thank them for their finan- 
cial support. Also we express our gratitude to the radiation laboratory of the Nuclear Science and Technology Research Institute (NSTRI).

\section{Statement of Ethics}

For this research (52d 9314), all institutional and national guidelines (adopted from the Declaration of Helsinki (1975) and The Society for Neuroscience Animal Care and Use guidelines (1998)) were approved for implementation by the Medical Ethics Committee, School of Medical Sciences of the Tarbiat Modares University (Tehran, Iran).

\section{Conflict of Interest Statement}

There are no conflicts of interest.

\section{Funding Sources}

This research was financially supported as a Master of Science thesis by a grant from Tarbiat Modares University.

\section{Author Contributions}

Maryam Mollaei Alamuti carried out the experiment, investigation, study design, and writing. Mehrdad Ravanshad supervised and designed the project and contributed to funding acquisition, writing, and editing the manuscript. Farahnaz Motamedi-Sedeh designed the study methodology and measurements, contributed to writing and editing the manuscript, and also rewrote the manuscript according to the reviewer comments. Arezoo Nabizadeh helped in writing and editing the manuscript. Elham Ahmadi designed the project, investigation, and contribute to writing and editing the manuscript. Seyedeh Maedeh Hosseini helped in data analysis and writing the manuscript.

\section{References}

1 Baj A, Colombo M, Headley JL, McFarlane JR, Liethof MA, Toniolo A. Post-poliomyelitis syndrome as a possible viral disease. Int J Infect Dis. 2015;35:107-16.

2 Rodríguez-Sánchez JA. Poliomyelitis after poliomyelitis: lights and shadows of the eradication an introduction. Hygiea Internationalis. 2015;11(1):7-31.

3 Bandyopadhyay AS, Garon J, Seib K, Orenstein WA. Polio vaccination: past, present and future. Future Microbiol. 2015;10(5):791808.

4 Hume AJ, Ames J, Rennick LJ, Duprex WP, Marzi A, Tonkiss J, et al. Inactivation of RNA viruses by gamma irradiation: a study on mitigating factors. Viruses. 2016;8(7):204.

5 Thompson EM, Brown M, Dobrikova E, Ramaswamy V, Taylor MD, McLendon R, et al. Poliovirus receptor (CD155) expression in pediatric brain tumors mediates oncolysis of medulloblastoma and pleomorphic xanthoastrocytoma. J Neuropathol Exp Neurol. 2018;77(8):696-702.

6 Reed LJ, Muench H. A simple method of estimating fifty percent endpoint. Am J Hyg. 1988;27:493-7.

7 Javan S, Motamedi-Sedeh F, Dezfoolian M, Wijewardana V. Evaluation of immune responses and histopathological effects against gamma irradiated avian influenza (Sub type H9N2) vaccine on broiler chicken. Braz Arch Biol Technol. 2020;63:e20200094.

8 Rouby S, Aboulsoud E. Evidence of intrauterine transmission of lumpy skin disease virus. Vet J. 2016;209:193-5.
9 Li YG, Tian FL, Gao FS, Tang XS, Xia C. Immune responses generated by Lactobacillus as a carrier in DNA immunization against footand-mouth disease virus. Vaccine. 2007; 25(5):902-11.

10 Whitby JL, Gelda AK. Use of incremental doses of cobalt 60 radiation as a means to determine radiation sterilization dose. J Parenter Drug Assoc. 1979;33(3):144-55.

11 da Silva Aquino KA. Sterilization by gamma irradiation, gamma radiation. In: Adrovic $\mathrm{F}$, editor. InTech. Available from: http://www. intechopen.com/books/gammaradiation/ sterilization-by-gamma-irradiation; 2012.

12 Hume AJ, Ames J, Rennick LJ, Duprex WP, Marzi A, Tonkiss J, et al. Inactivation of RNA viruses by gamma irradiation: a study on mitigating factors. Viruses. 2016;8(7):204-12.

13 Wang W, Yu Z, Su W. Ion irradiation and biomolecular radiation damage II. Indirect effect: Cornell University; 2010. arXiv: 1004.4394 [physics.bio-ph].

14 Parker EP, Molodecky NA, Pons-Salort M, O'Reilly KM, Grassly NC. Impact of inactivated poliovirus vaccine on mucosal immunity: implications for the polio eradication endgame. Expert Rev Vaccines. 2015;14(8): 1113-23.

15 Global Polio Iradication Initiative. Polio eradication \& endgame strategic plan 2013-2018. 2013.

16 Motamedi-Sedeh F, Afsharnasab M, Heidarieh M. Immunization of Litopenaeus vannamei shrimp against white spot syndrome virus (WSSV) by gamma-irradiated WSSV plus Vibrio paraheomolyticus. Vaccine Res. 2016; 3(1):15-20.
17 Motamedi-Sedeh F, Soleimanjahi H, Jalilian AR, Mahravani H, Shafaee K, Sotoodeh M, et al. Development of protective immunity against inactivated Iranian isolate of footand-mouth disease virus type O/IRN/2007 using gamma ray-irradiated vaccine on $\mathrm{BALB} / \mathrm{c}$ mice and guinea pigs. Intervirology. 2015;58(3):190-6.

18 Salehi B, Motamedi-Sedeh F, Madadgar O, Khalili I, Ghalyan Chi Langroudi A, Unger H, et al. Analysis of antigen conservation and inactivation of gamma-irradiated avian influenza virus subtype H9N2. Acta Microbiol Immunol Hung. 2018;65(2):163-71.

19 Motamedi-Sedeh F, Afsharnasab M, Heidarieh M, Tahami SM. Protection of Litopenaeus vannamei against white spot syndrome virus by electron-irradiated inactivated vaccine and prebiotic immunogen. Radiat Phys Chem. 2017;130:421-5.

20 Stauffer F, El-Bacha T, Da-Poian AT. Advances in the development of inactivated virus vaccines Recent Pat Antiinfect Drug Discov 1; 2006. p. 291-6.

21 Furuya Y, Regner M, Lobigs M, Koskinen A, Müllbacher A, Alsharifi M. Effect of inactivation method on the cross-protective immunity induced by whole 'killed' influenza a viruses and commercial vaccine preparations. J Gen Virol. 2010;91(Pt 6): 1450-60.

22 David SC, Lau J, Singleton EV, Babb R, Davies J, Hirst TR, et al. The effect of gamma-irradiation conditions on the immunogenicity of whole-inactivated influenza a virus vaccine. Vaccine. 2017;35(7):1071-9. 